\title{
Obtención de proteínas de engraulis ringens ringens (anchoveta) y trahurus murphi (jurel), para consumo humano directo
}

Obtaining proteins from engraulis ringens ringens (anchoveta) and trahurus murphi (jurel), for direct human consumption

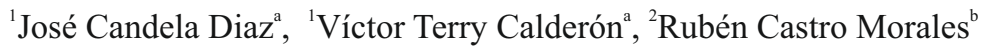

\section{RESUMEN}

Para obtener un concentrado de proteínas a partir del musculo de pescado (jurel), se procede a una operación de molienda de los filetes seguido de una extracción en frio de agua y grasa, para lo cual se utilizó al etanol a $96^{\circ} \mathrm{C}$, como agente deshidratante y posteriormente se procede a extraer la grasa utilizando siete extracciones con hexano. Posteriormente se elimina el hexano de la muestra utilizando aire caliente a $50{ }^{\circ} \mathrm{C}$, seguido de una molienda y empacado. La composición física de la muestra de jurel fue de 17,30\% de Cabezas, 11,20\% de vísceras,espinas 16,00 , piel y aletas 5,7\% y filetes $47 \%$. La composición química del filete de jurel fue de: agua de 68,18 a 69,38\%, proteínas de 24,17 a 20,93\%, grasa de 5,21 a $9,12 \%$, y cenizas de 0,53 a 1,45\% . El resultado con etanol dio una eliminación de agua del $35,07 \%$, y donde el concentrado de proteínas fue de 88,31 a $89,91 \%$, de grasa de 0,88 a $0,98 \%$, cenizas de 2,45 a $2,78 \%$ y agua de 5,02 a 5,50, el concentrado de pescado obtenido califica como del tipo B, al contener grasa entre $0,75 \%$ y $3,00 \%$.

Palabras clave: concentrado proteico, filete de jurel, extracción solido liquido

\begin{abstract}
To obtain a concentrate of proteins from muscle of fish (mackerel), is a fillet milling operation followed by extraction in cold, which was ethanol at $96^{\circ} \mathrm{C}$, such as dehydrating agent and subsequently proceed to extract fat using seven extraction with hexane. Subsequently removed the hexane of the sample using hot air at $50^{\circ} \mathrm{C}$, followed by a grinding and packaging. The physical composition of the sample of mackerel was $17.30 \%$ of heads, $11.20 \%$ of viscera, spines 16,00 , skin and fins $5.7 \%$ and $47 \%$ fillets. The chemical composition of the mackerel fillet was: water of 68.18 to $69.38 \%, 24.1720 .93 \%$ proteins, fat 5.21 to $9.12 \%$ and 0.53 to $1.45 \%$ ash. The result with ethanol gave an elimination of $35.07 \%$ water, and where protein concentrate was $88,3189,91 \%$, fat from 0.88 to $0.98 \%$, ashes of 2.45 to $2.78 \%$ and water from 5.02 to 5.50 , concentrate retrieved fish qualifies as type B, containing fat between $0.75 \%$ and $3.00 \%$.
\end{abstract}

keyword: concentrated protein, horse mackerel fillet.

${ }^{1}$ Universidad Nacional Federico Villareal, Lima - Perú. ${ }^{2}$ Universidad Le Cordon Bleu, Lima - Perú. ${ }^{\mathrm{a}}$ Ingeniero Pesquero. ${ }^{\mathrm{b}}$ Ing. Alimentario. 


\section{INTRODUCCIÓN}

En la presente investigación, el método para la obtención de concentrados proteicos a partir del Trahurus murphi (jurel), sin intervención el calor durante este proceso, debido al empleo del etanol el actúa como un agente deshidratante al realizarse la mezcla respectiva. Posteriormente se utiliza, un solvente de grasa que este proyecto fue el hexano. Cabe hacer notar que en estas dos operaciones no se suministra calor. Con lo cual este método hace que la proteína tratada no sufra alteraciones, como es el caso de la desnaturalización térmica, o perdida de aminoácidos sensibles al calor. Una vez extraída el agua y el aceite del sistema, por acción de los solventes, se procede a eliminar los residuales, del producto tratado, para lo cual, este, se coloco en un secador de arrastre el mismo que trabaja temperaturas menores a los 50 ${ }^{\circ} \mathrm{C}$, obteniéndose un Concentrado proteico de pescado a partir de filetes de jurel.

Es importante mencionar que la extracción de las proteínas del pescado, para el consumo humano, es un objetivo a lograr como consecuencia de la escasez mundial de proteínas, incremento de la población, la mayor demanda alimenticia, la desnutrición infantil y en la tercera edad (adultos mayores). Mucho de los productos animales son difíciles de obtener; siendo su costo muy elevado, la exigua economía de países en vías de desarrollo, no puede soportar, ni estimular por otros medios (Guillén, 1980).

De acuerdo a los estudios y análisis, los científicos están plenamente de acuerdo, que el método más real y capaz de ofrecer los mejores resultados, es mediante la utilización de los peces, si se toma en cuenta que el déficit anual de proteínas en el mundo es de 20 millones de toneladas, se calcula que los océanos pueden suministrar anualmente entre 30 a 40 millones de toneladas de proteína pura, sin generar peligro de extinción ( Nishio ,1999).

Otro de los aspectos mas importantes, sustantivo del problema, consiste en lograr que el producto proteínico sea aceptado y consumido por la población, particularmente, por aquellos sectores que más lo necesitan (niños, adulto mayores, madres gestantes, poblaciones rurales, asentamientos humanos etc.); en este aspecto, los técnicos y especialistas coinciden en la necesidad de adaptar el producto concentrado, a las costumbres dietéticas de cada zona, región o lugar, de acuerdo a los gustos de cada sector, evitando cualquier distorsión que sería de efecto negativo.(Nishio,(1999). Una recomendación como medida elemental sería, la mezcla con harina, para su inclusión en el pan, galletas, fideos, pastas, etc. Así como en elaboración de salsas, condimentos u otros preparados, con el fin de vencer los eventuales perjuicios y reticencias obsoletas, carecen de fundamento cuando menos razonable. Segura (1994). 
El método más común para eliminar el agua de los tejidos usa etanol como agente deshidratante. Deshidrata el tejido pasando a través de series de etanol graduado empezando con un 30\% y acabando con etanol 100\% (200 grados, anhidro). Para todas las diluciones excepto para la dilución final de etanol, debe ser usado etanol de $95 \%$ comercial. Desde cada paso en la serie la concentración es más relativa que absoluta, tratar el alcohol de $95 \%$ como de $100 \%$ cuando calcules las diluciones. Diluir con agua destilada a la proporción adecuada. Puede que quieras incluir una sustancia que escarbé el agua (una molécula colador por ejemplo) en la última solución de etanol para asegurarse que el tratamiento final con etanol absoluto use etanol anhidro. Date cuenta de la cantidad de la concentración de agua del fijador usado y comienza la deshidratación a esa concentración. El FAA generalmente es etanol al 50\%, por tanto comenzar la deshidratación al 50\% para salvar los pasos de deshidratación. Finalmente, la mayoría de los fijadores requieren un paso de lavado antes del procedimiento de deshidratación. Lavar los tejidos con la solución fijadora menos el fijador. La deshidratación de tejidos puede volverlos transparentes. En vez de verlos en el bloque de parafina o plástico, teñir los tejidos con Safranina O al 1\%, Eosina Y, o Azul de Timol en el penúltimo paso de etanol o acetona al 100\%.(http://www.euita.upv.es/varios/b iologia/tecnicas_de_histologia_vegetal/9
Documentos/Deshidratacion.htm). La Organización para alimentación ty la agricultura de las Naciones Unidas definen tres tipos de Concentrados proteicos: Tipo A: un polvo prácticamente insípido que tiene un máximo de de materias grasas de $0,75 \%$. Topo B: una harina que no tiene limites específicos en cuanto a olor o sabor y con un contenido graso máximo del 3,0\% y el Tipo C que es la harina de pescado tipo prime. https://es.scribd.com/doc/57541904/Aisl ados-y-Concentrados-Proteicos-dePescado

El contenido de grasa se especifica al definir los tipos de concentrados proteicos porque la grasa oxidada cuando se puede producir un sabor fuerte, a menudo rancio, en el producto. El contenido de proteína del concentrado depende de la materia prima utilizada y la medida en que el agua se ha eliminado, pero los productos suelen contener al menos el 65 por ciento de proteínas y, en tipo A, hasta el 80 por ciento.

El objetivo del presente estudio es determinar la tecnología a nivel de laboratorio para la extracción de proteínas, empleando como solventes al etanol y al hexano, de forma que el concentrado proteico de pescado pueda tener un contenido graso menor al 1,00\%.

\section{MATERIALY MÉTODOS}

\section{Muestra}

La Muestra, el jurel (Trahurus murphi) fue tomada en el terminal pesquero de 
Ventanilla, donde los transportes refrigerados o insulados proveen del recurso a Lima.

\section{Materiales}

Los materiales utilizados fueron: Ictiómetro, balanza OHAUS de $0,1 \mathrm{~g}$ de aproximación, con los cuales se realizaron las medidas respectivas (longitud y peso). Molino de 25 litros, secadora de arrastre de aire, extractor sólido - liquido. Para la extracción de la grasa a nivel de laboratorio se utilizo hexano y para la deshidratación del recurso etanol de grado alimentario. El análisis de regresión que correlaciona los datos respectivos y los valores medio se realizaron con el software EXCEL 2000.
Los análisis químicos fueron efectuados en el Laboratorio de Tecnología de Alimentos de acuerdo a los métodos de la AOAC (1984):

1. Porcentaje de proteínas

2. Porcentaje de cenizas

3. Porcentaje de grasa

4. Porcentaje de Humedad.

\section{Procedimiento}

Método utilizado para la extracción empleando solventes:

En la siguiente tabla se muestra la secuencia de operaciones que se realizaron para la obtención del concentrado proteico.

Tabla 1. Programa para realizar el concentrado proteico de pescado

\begin{tabular}{lll}
\hline $\mathrm{N}^{\mathrm{o}}$ & OPERACIONES & \multicolumn{1}{c}{ DESCRICIÓN } \\
\hline 1 Molienda & $\begin{array}{l}\text { Objetivo: Reducir el tamaño de partícula del pescado, con } \\
\text { el fin de que los solventes puedan actuar más } \\
\text { rápidamente. Equipo: Molino vertical }\end{array}$
\end{tabular}

2 Extracción con etanol Descripción: Representa la mezcla de etanol con el recurso molido en una proporción de 1,0 de material por 1,5 de etanol $96^{\circ}$. Objetivo: Precipitación de las proteínas, deshidratación y extracción del material soluble del material Equipo: Molino vertical con un tiempo de 5 minutos

3 Filtración Objetivo: Separación de las proteínas del material soluble del material, formándose dos flujos conformados por una fase liquida (extracto alcohólico) y una fase sólida (cake proteico)

4 Primera extracción Objetivo: La fase sólida procedente de la filtración se trata con hexano con hexano, en una proporción de 1 a 1 , por espacio de 15 minutos. Con lo cual la grasa presente en el músculo pasa al solvente. Equipo: Molino vertical.

5 Filtración

6 Segunda extracción con hexano
Separación de fases

Objetivo: La fase sólida procedente de la filtración se trata con hexano, en una proporción de 1 a 1 , por espacio de 15 minutos. Con lo cual la grasa presente en el músculo pasa al solvente. Equipo: Molino vertical 
7 Filtración Separación de fases

8 Tercera Objetivo: La fase sólida procedente de la filtración se trata con extracción hexano, en una proporción de 1 a 1 , por espacio de 15 minutos. con hexano Con lo cual la grasa presente en el músculo pasa al solvente. Equipo: Molino vertical

9 Filtración Separación de fases

10 Cuarta Objetivo: La fase sólida procedente de la filtración se trata con extracción hexano, en una proporción de 1 a 1 , por espacio de 15 minutos. con hexano Con lo cual la grasa presente en el músculo pasa al solvente. Equipo: Molino vertical

11 Filtración Separación de fases

12 Quinta Objetivo: La fase sólida procedente de la filtración se trata con extracción hexano, en una proporción de 1 a 1 , por espacio de 15 minutos. con hexano Con lo cual la grasa presente en el músculo pasa al solvente.

Equipo: Molino vertical

13 Filtración Separación de fases

14 Sexta Objetivo: La fase sólida procedente de la filtración se trata con extracción hexano, en una proporción de 1 a 1 , por espacio de 15 minutos. con hexano Con lo cual la grasa presente en el músculo pasa al solvente.

Equipo: Molino vertical

15 Filtración Separación de fases

16 Desolventización Objetivo: Eliminar los solventes residuales en la masa tratada de pesca

17 Molienda Objetivo: Reducción de tamaño partícula del Concentrado de pescado

18 Envasado Objetivo: Proteger el material obtenido en el proceso

Figura 1.Diagrama para la extracción sólido-líquido(etanol-masa pulpeada de anchoveta)

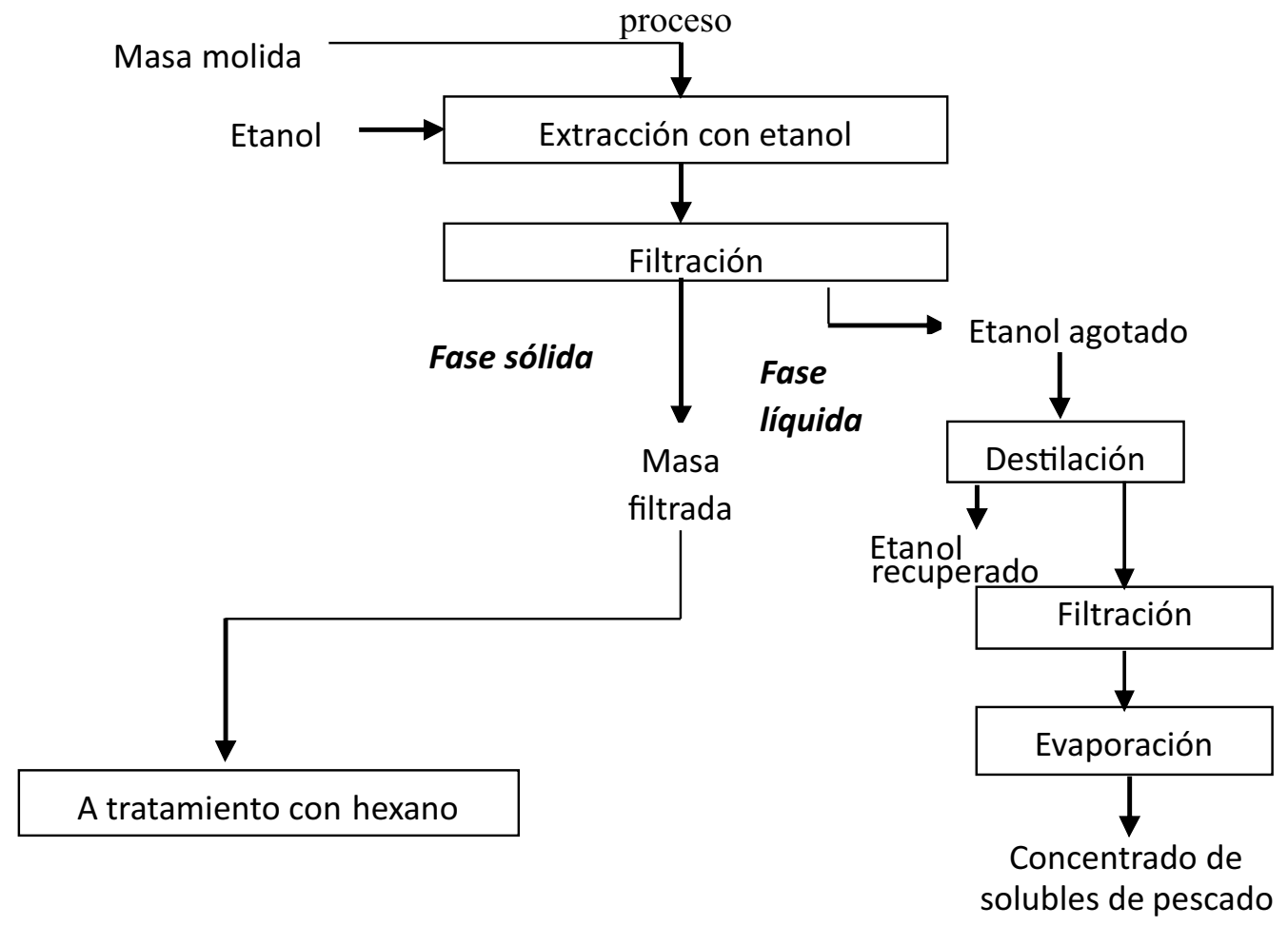


Figura 2. Diagrama para la extracción con hexano

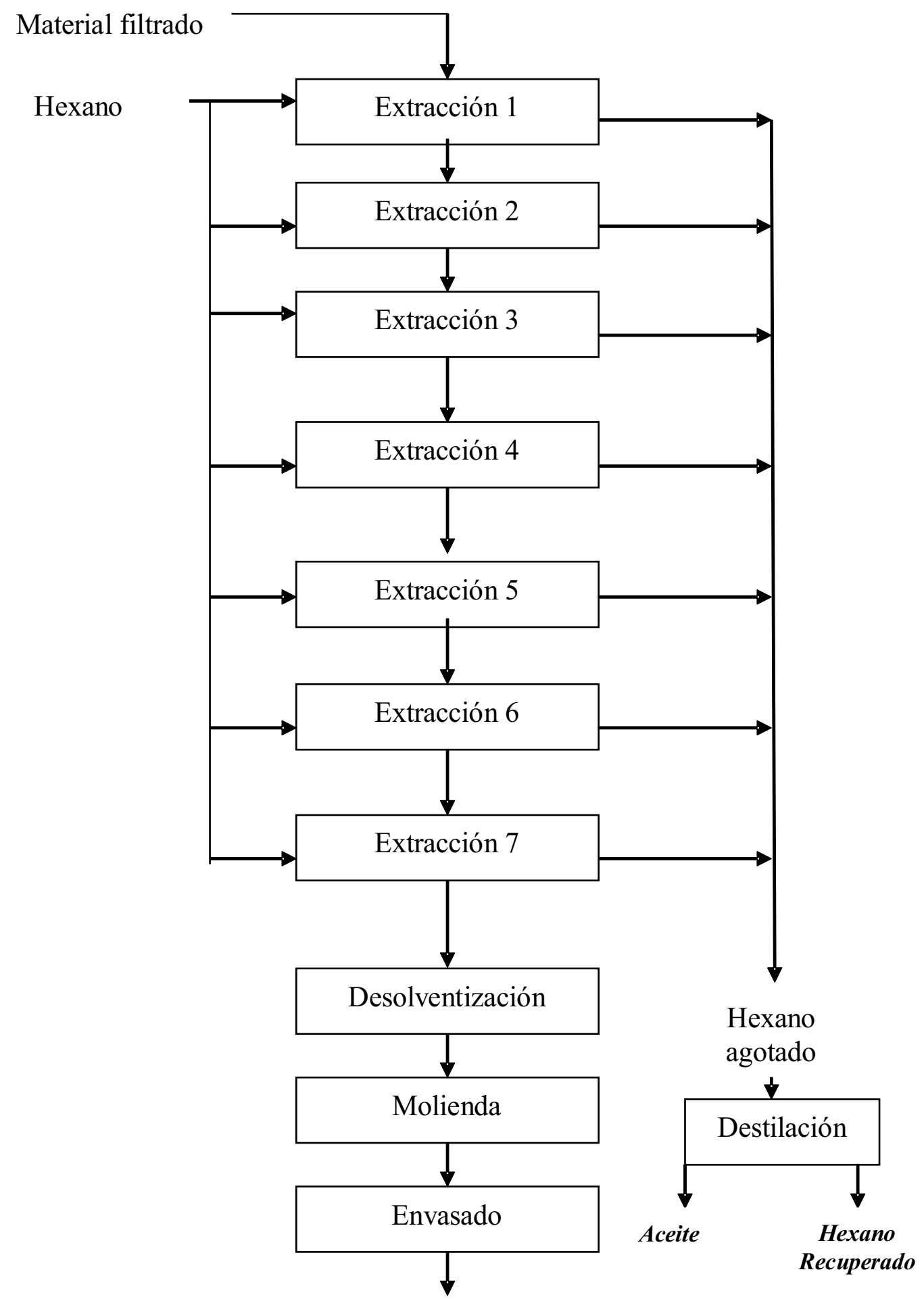

Concentrado proteico 


\section{Resultados}

Las medidas biométricas del jurel

Tabla 2. Medidas biométricas del jurel

\begin{tabular}{ccc}
\hline Muestra & Longitud(L) & Peso(W) \\
\hline $\mathrm{N}^{\mathrm{o}}$ & $\mathrm{cm}$ & $\mathrm{g}$ \\
& Primer muestreo & \\
1 & 37.00 & 424.00 \\
2 & 35.80 & 331.50 \\
3 & 38.00 & 480.00 \\
4 & 36.40 & 423.00 \\
5 & 37.80 & 420.00 \\
6 & 38.40 & 492.00 \\
7 & 39.00 & 490.00 \\
8 & 40.20 & 496.00 \\
9 & 38.20 & 484.00 \\
10 & 35.70 & 315.00 \\
11 & 40.70 & 501.00 \\
12 & 35.00 & 310.00 \\
& Segundo muestreo & \\
13 & 35.40 & 311.00 \\
14 & 37.10 & 422.00 \\
15 & 35.60 & 312.00 \\
16 & 36.00 & 421.00 \\
17 & 37.40 & 411.00 \\
18 & 37.10 & 425.00 \\
19 & 37.80 & 448.00 \\
20 & 35.00 & 340.00 \\
21 & 39.00 & 480.00 \\
22 & 35.00 & 312.00 \\
23 & 36.00 & 424.00 \\
24 & 32.50 & 308.00 \\
25 & 36.80 & 421.00 \\
& $30 r c e r$ muestreo & \\
26 & 35.00 & 389.20 \\
27 & 34.90 & 311.00 \\
28 & 33.20 & 351.00 \\
29 & 36.80 & 421.00 \\
30 & 35.80 & 421.00 \\
31 & 37.60 & 441.30 \\
32 & 34.30 & 337.80 \\
33 & 38.70 & 475.30 \\
34 & 34.30 & 309.80 \\
35 & 32.90 & 362.30 \\
36 & & 441.00 \\
\hline & &
\end{tabular}


Tabla 3. Datos para el análisis de regresión

\begin{tabular}{cccl}
\hline Longitud $(\mathrm{L})$ & Peso $(\mathrm{W})$ & & \\
\hline $\mathrm{cm}$ & $\mathrm{g}$ & $\log (\mathrm{L})$ & $\mathrm{Log}(\mathrm{W})$ \\
32.50 & 308.00 & 1.5118834 & 2.4885507 \\
32.90 & 362.30 & 1.5171959 & 2.5590683 \\
33.20 & 351.00 & 1.5211381 & 2.5453071 \\
34.30 & 337.80 & 1.5352941 & 2.5286596 \\
34.30 & 309.80 & 1.5352941 & 2.4910814 \\
34.90 & 311.00 & 1.5428254 & 2.4927604 \\
35.00 & 310.00 & 1.5440680 & 2.4913617 \\
35.00 & 340.00 & 1.5440680 & 2.5314789 \\
35.00 & 312.00 & 1.5440680 & 2.4941546 \\
35.00 & 389.20 & 1.5440680 & 2.5901728 \\
35.40 & 311.00 & 1.5490033 & 2.4927604 \\
35.60 & 312.00 & 1.5514500 & 2.4941546 \\
35.70 & 315.00 & 1.5526682 & 2.4983106 \\
35.80 & 331.50 & 1.5538830 & 2.5204835 \\
35.80 & 421.00 & 1.5538830 & 2.6242821 \\
36.00 & 421.00 & 1.5563025 & 2.6242821 \\
36.00 & 424.00 & 1.5563025 & 2.6273659 \\
36.40 & 423.00 & 1.5611014 & 2.6263404 \\
36.80 & 421.00 & 1.5658478 & 2.6242821 \\
36.80 & 421.00 & 1.5658478 & 2.6242821 \\
37.00 & 424.00 & 1.5682017 & 2.6273659 \\
37.10 & 422.00 & 1.5693739 & 2.6253125 \\
37.10 & 425.00 & 1.5693739 & 2.6283889 \\
37.40 & 411.00 & 1.5728716 & 2.6138418 \\
37.60 & 441.30 & 1.5751878 & 2.6447339 \\
37.60 & 441.00 & 1.5751878 & 2.6444386 \\
37.80 & 420.00 & 1.5774918 & 2.6232493 \\
37.80 & 448.00 & 1.5774918 & 2.6512780 \\
38.00 & 480.00 & 1.5797836 & 2.6812412 \\
38.20 & 484.00 & 1.5820634 & 2.6848454 \\
38.40 & 492.00 & 1.5843312 & 2.6919651 \\
38.70 & 475.30 & 1.5877110 & 2.6769678 \\
39.00 & 490.00 & 1.5910646 & 2.6901961 \\
39.00 & 480.00 & 1.5910646 & 2.6812412 \\
40.20 & 496.00 & 1.6042261 & 2.6954817 \\
40.70 & 501.00 & 1.6095944 & 2.6998377 \\
\hline & & & \\
\hline
\end{tabular}


Figura 3. Medidas biométricas (longitud en función del peso)

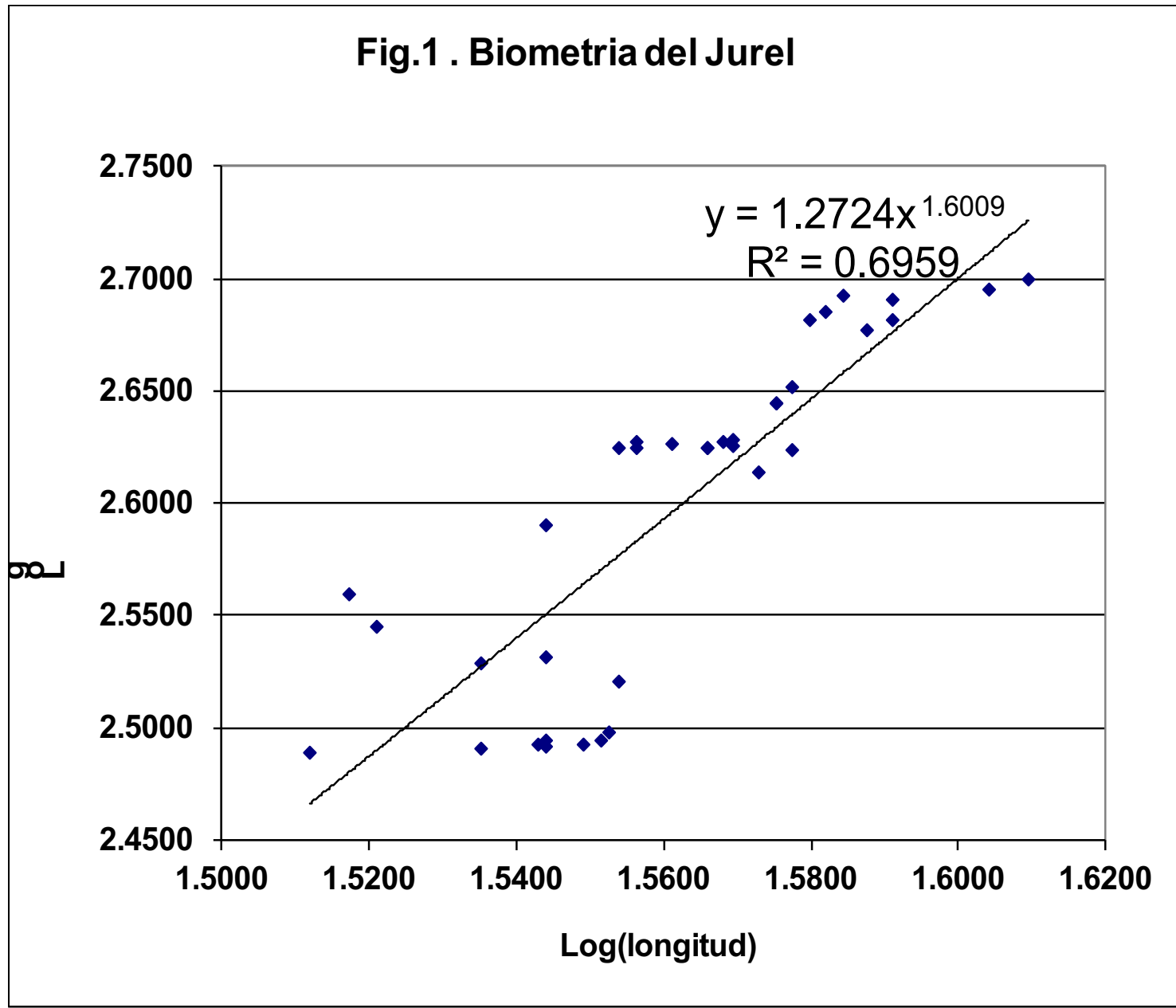

$$
\mathrm{L}=1,2724 W^{1,6009}
$$

Composición química proximal de los filetes de jurel

Tabla 4. Composición química de los filetes de jurel

\begin{tabular}{cccccc}
\hline $\mathrm{N}^{\mathrm{o}}$ & \%agua & \% grasa & \% proteinas & \% sales & \% no determinado \\
\hline 1 & 68.18 & 8.35 & 22.14 & 0.73 & 0.80 \\
2 & 69.38 & 6.41 & 22.12 & 1.45 & 0.64 \\
3 & 67.13 & 8.37 & 23.43 & 0.48 & 0.59 \\
4 & 70.12 & 5.21 & 22.98 & 1.28 & 0.41 \\
5 & 68.17 & 8.45 & 22.30 & 0.87 & 0.21 \\
6 & 68.65 & 8.38 & 22.27 & 0.53 & 0.17 \\
7 & 66.14 & 9.13 & 22.34 & 1.67 & 0.72 \\
8 & 68.32 & 6.43 & 23.43 & 1.25 & 0.57 \\
9 & 68.92 & 7.33 & 22.74 & 0.76 & 0.25 \\
10 & 68.87 & 6.12 & 24.17 & 0.71 & 0.13 \\
11 & 68.77 & 8.62 & 20.93 & 1.34 & 0.34 \\
12 & 67.12 & 6.94 & 24.86 & 0.72 & 0.36 \\
13 & 68.87 & 6.12 & 24.37 & 0.53 & 0.11 \\
14 & 69.31 & 7.15 & 22.33 & 0.75 & 0.46 \\
15 & 69.32 & 7.24 & 22.45 & 0.78 & 0.21 \\
\hline
\end{tabular}


Composición física del jurel

Tabla 5. Peso de los componentes físicos muestra 1 en (g)

\begin{tabular}{lrrrrrrrrr}
\hline Componente & 1 & \multicolumn{1}{c}{2} & \multicolumn{1}{c}{3} & \multicolumn{1}{c}{4} & \multicolumn{1}{l}{5} & \multicolumn{1}{l}{6} & \multicolumn{1}{l}{7} & \multicolumn{1}{l}{8} & \multicolumn{1}{l}{9} \\
\hline Cabeza & 84.0 & 59.7 & 86.4 & 76.1 & 75.6 & 88.6 & 88.2 & 89.3 & 87.1 \\
Vísceras & 46.2 & 39.8 & 57.6 & 50.8 & 50.4 & 59.0 & 58.8 & 59.5 & 58.1 \\
Espinas & 35.2 & 58.0 & 84.0 & 74.0 & 73.5 & 86.1 & 85.8 & 86.8 & 84.7 \\
Piel & 17.4 & 11.6 & 16.8 & 14.8 & 14.7 & 17.2 & 17.2 & 17.4 & 16.9 \\
Aletas & 14.0 & 8.3 & 12.0 & 10.6 & 10.5 & 12.3 & 12.3 & 12.4 & 12.1 \\
Filetes & 217.5 & 169.1 & 244.8 & 215.7 & 214.2 & 250.9 & 249.9 & 253.0 & 246.8 \\
Otros & 9.8 & 7.6 & 11.0 & 9.7 & 9.7 & 11.3 & 11.3 & 11.4 & 11.1 \\
\hline
\end{tabular}

Tabla 6. Peso de los componentes físicos de la muestra 2 en (g)

\begin{tabular}{lcrrrrrrrr}
\hline Componente & 10 & 11 & \multicolumn{1}{c}{12} & \multicolumn{1}{c}{13} & \multicolumn{1}{c}{14} & \multicolumn{1}{c}{15} & \multicolumn{1}{c}{16} & \multicolumn{1}{c}{17} & \multicolumn{1}{c}{18} \\
\hline Cabeza & 56.0 & 76.0 & 56.2 & 75.8 & 74.0 & 76.5 & 80.6 & 61.2 & 86.4 \\
Vísceras & 37.3 & 50.6 & 37.4 & 50.5 & 49.3 & 51.0 & 53.8 & 40.8 & 57.6 \\
Espinas & 54.4 & 73.9 & 54.6 & 73.7 & 71.9 & 74.4 & 78.4 & 59.5 & 84.0 \\
Piel & 10.9 & 14.8 & 10.9 & 14.7 & 14.4 & 14.9 & 15.7 & 11.9 & 16.8 \\
Aletas & 7.8 & 10.6 & 7.8 & 10.5 & 10.3 & 10.6 & 11.2 & 8.5 & 12.0 \\
Filetes & 158.6 & 215.2 & 159.1 & 214.7 & 209.6 & 216.8 & 228.5 & 173.4 & 244.8 \\
Otros & 7.2 & 9.7 & 7.2 & 9.7 & 9.5 & 9.8 & 10.3 & 7.8 & 11.0 \\
\hline
\end{tabular}

Tabla 7. Peso de los componentes físicos de la muestra 3 en (g)

\begin{tabular}{lcrrrrrrrr}
\hline Componente & 19 & \multicolumn{1}{c}{20} & \multicolumn{1}{c}{21} & \multicolumn{1}{c}{22} & \multicolumn{1}{c}{23} & \multicolumn{1}{c}{24} & \multicolumn{1}{c}{25} & \multicolumn{1}{c}{26} & \multicolumn{1}{c}{27} \\
\hline Cabeza & 56.0 & 63.2 & 75.8 & 76.1 & 79.4 & 60.8 & 85.6 & 55.8 & 65.2 \\
Vísceras & 37.3 & 42.1 & 50.5 & 50.8 & 53.0 & 40.5 & 57.0 & 37.2 & 43.4 \\
Espinas & 54.4 & 61.4 & 73.7 & 74.0 & 77.2 & 59.1 & 83.2 & 54.2 & 63.4 \\
Piel & 10.9 & 12.3 & 14.7 & 14.8 & 15.4 & 11.8 & 16.6 & 10.8 & 12.7 \\
Aletas & 7.8 & 8.8 & 10.5 & 10.6 & 11.0 & 8.4 & 11.9 & 7.7 & 9.1 \\
Filetes & 158.6 & 179.0 & 214.7 & 215.7 & 225.1 & 172.3 & 242.4 & 158.0 & 184.6 \\
Otros & 7.2 & 8.1 & 9.7 & 9.7 & 10.1 & 7.8 & 10.9 & 7.1 & 8.3 \\
\hline
\end{tabular}

Composición física promedio

Tabla 8. Resultado del análisis de la composición física

\begin{tabular}{lc}
\hline \multicolumn{1}{c}{ Componentes } & $\%$ \\
\hline Cabeza & 17,30 \\
Vísceras & 11,20 \\
Espinas & 16,00 \\
Piel & 3,30 \\
Aletas & 2,40 \\
Filetes & 47,70 \\
Otros & 2,1 \\
\hline
\end{tabular}


Tabla 9. Resumen de los resultados

\begin{tabular}{|c|c|c|}
\hline $\mathrm{N}^{\mathrm{o}}$ & Descripción & Valores \\
\hline \multirow[t]{3}{*}{1} & Longitud promedio & Longitud_promedio $=36,5 \pm 0,65$ \\
\hline & Peso promedio & 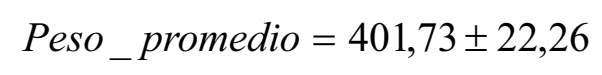 \\
\hline & Ecuación & $L=1,2724 . W^{1,6009}$ \\
\hline \multirow[t]{5}{*}{2} & $\begin{array}{l}\text { Composición química } \\
\text { - \%humedad }\end{array}$ & $68,48 \pm 0,57$ \\
\hline & - \%grasa & $7,35 \pm 0,64$ \\
\hline & - \%proteínas & $22,86 \pm 0,57$ \\
\hline & - $\%$ sales & $0,92 \pm 0,21$ \\
\hline & - $\%$ no determinados & $0,398 \pm 0,12$ \\
\hline \multirow[t]{7}{*}{3} & $\begin{array}{l}\text { Composiciones físicas } \\
\text { - } \% \text { Cabeza }\end{array}$ & 11,30 \\
\hline & - \%Vísceras & 11,20 \\
\hline & - $\%$ Espinas & 16,00 \\
\hline & - $\%$ Piel & 3,30 \\
\hline & - \%Aletas & 2,40 \\
\hline & - $\%$ Otros & 2,10 \\
\hline & - $\%$ Filetes & 47,70 \\
\hline
\end{tabular}

Se observa en la Tabla Resumen de los estudios preliminares que del recurso se puede aprovechar el 47,70\%, como filetes (parte comestible), para la elaboración del Concentrado, el mismo que tiene un contenido de proteínas promedio de $22,86 \%$ y 7,35\% de grasa. 
Rendimiento de filetes de jurel

Tabla 10. Rendimiento en filetes

\begin{tabular}{cccccc}
\hline Muestra & $\begin{array}{c}\text { Peso } \\
\text { entero }(\mathrm{g})\end{array}$ & $\begin{array}{c}\text { Peso } \\
\text { filete }(\mathrm{g})\end{array}$ & $\begin{array}{c}\text { Peso } \\
\text { residuo }(\mathrm{g})\end{array}$ & $\begin{array}{c}\text { Rendimiento } \\
\text { ilete }(\%)\end{array}$ & $\begin{array}{c}\text { Residuos } \\
(\%)\end{array}$ \\
\hline 1 & 1430 & 700 & 730 & 48,95 & 51,05 \\
2 & 1440 & 590 & 850 & 40,97 & 59,03 \\
3 & 2228 & 1250 & 978 & 56,10 & 43,90 \\
4 & 1780 & 890 & 890 & 50,00 & 50,00 \\
5 & 2120 & 1010 & 1110 & 47,64 & 52,36 \\
6 & 1750 & 830 & 920 & 47,43 & 52,57 \\
7 & 1840 & 685 & 1155 & 37,23 & 62,77 \\
8 & 1570 & 710 & 860 & 45,22 & 54,78 \\
9 & 1025 & 430 & 595 & 41,95 & 58,05 \\
10 & 2690 & 1420 & 1270 & 52,79 & 47,21 \\
11 & 1780 & 790 & 990 & 44,38 & 55,62 \\
12 & 1290 & 460 & 830 & 35,66 & 64,34 \\
13 & 1300 & 510 & 790 & 39,23 & 60,77 \\
Total & 22243 & 10275 & 11968 & 45,20 & 54,80 \\
\hline
\end{tabular}

Ensayos con extracción del etanol

Tabla 11. Tratamiento con etanol $\left(96^{\circ} \mathrm{GL}\right)$

\begin{tabular}{cccccccc}
\hline Muestra & $\begin{array}{c}\text { Peso } \\
\text { filete }(\mathrm{g})\end{array}$ & $\begin{array}{c}\text { Etanol } \\
\text { Volumen }\end{array}$ & $\begin{array}{c}\text { Sólido } \\
\text { filtrado }(\mathrm{g})\end{array}$ & $\begin{array}{c}\text { Pérdida } \\
\text { peso }(\mathrm{g})\end{array}$ & $\begin{array}{c}\text { Etanol } \\
\text { filtrado }\end{array}$ & $\begin{array}{c}\text { Grado } \\
\text { Alcohólico }\end{array}$ & $\begin{array}{c}\text { Pérdida } \\
\text { ETOH }\end{array}$ \\
\hline 1 & 700 & 700 & 455 & 245 & 595 & 66 & 105 \\
2 & 590 & 600 & 380 & 210 & 510 & 67 & 90 \\
3 & 1250 & 1300 & 810 & 440 & 1100 & 66 & 200 \\
4 & 890 & 900 & 550 & 340 & 770 & 65 & 130 \\
5 & 1010 & 1100 & 650 & 360 & 945 & 65 & 155 \\
6 & 830 & 850 & 520 & 310 & 720 & 64 & 130 \\
7 & 685 & 700 & 450 & 235 & 603 & 66 & 97 \\
8 & 710 & 720 & 460 & 250 & 612 & 67 & 108 \\
9 & 430 & 450 & 278 & 152 & 385 & 66 & 65 \\
10 & 1420 & 1450 & 923 & 497 & 1223 & 65 & 227 \\
11 & 790 & 800 & 513 & 277 & 680 & 65 & 120 \\
12 & 460 & 470 & 310 & 150 & 410 & 66 & 60 \\
13 & 510 & 550 & 320 & 190 & 466 & 64 & 84 \\
Total & 10275 & 10590 & 6619 & 3656 & 9019 & & 1571 \\
\hline
\end{tabular}


Resultados del tratamiento con etanol

Tabla 11. Balance de materiales

\begin{tabular}{clcc}
\hline $\mathrm{N}^{\mathrm{o}}$ & \multicolumn{1}{c}{ Descripción } & Valores & Unidad \\
\hline 1 & Filete de jurel molido & 10,275 & $\mathrm{~kg}$ \\
2 & Etanol empleado & 10,59 & litros \\
3 & $\begin{array}{l}\text { Peso de jurel tratada con ETOH } \\
\text { (Filtrado). }\end{array}$ & 6,62 & $\mathrm{~kg}$ \\
& Etanol agotado (filtrado) & 9,02 & litros \\
5 & Perdida de peso del jurel & 3,66 & $\mathrm{~kg}$ \\
7 & Etanol recuperado & 8,92 & litros \\
8 & Perdida de etanol & 1,57 & litros \\
9 & \% de perdida de etanol & 8.05 & $\%$ \\
\hline
\end{tabular}

Tratamiento con hexano.

Tabla 12. Extracción de grasa empleando Hexano

\begin{tabular}{ccccccr}
\hline Muestra & $\begin{array}{c}\mathrm{N}^{\mathrm{o}} \\
\text { extracciones }\end{array}$ & $\begin{array}{c}\text { Peso } \\
\text { Filete }(\mathrm{g})\end{array}$ & $\begin{array}{c}\text { Hexano } \\
\text { volumen }\end{array}$ & $\begin{array}{c}\text { Peso } \\
\text { Final }(\mathrm{g})\end{array}$ & Rendimiento & $\begin{array}{c}\text { \%grasa } \\
\text { residual }\end{array}$ \\
\hline 1 & 0 & 700 & & 139,72 & 5,01 & 11,21 \\
2 & & 455 & 500 & 89,22 & 5,1 & \\
3 & 1 & 380 & 400 & 69,09 & 5,5 & 5,23 \\
4 & & 810 & 800 & 150,00 & 5,4 & \\
5 & 2 & 550 & 500 & 103,77 & 5,3 & 2,35 \\
6 & & 650 & 700 & 120,37 & 5,4 & \\
7 & 3 & 520 & 500 & 94,55 & 5,5 & 1,85 \\
8 & & 450 & 500 & 81,82 & 5,5 & \\
9 & 4 & 460 & 500 & 82,14 & 5,6 & 0,9 \\
10 & & 278 & 300 & 47,93 & 5,8 & \\
11 & 5 & 923 & 1000 & 161,93 & 5,7 & 0,81 \\
12 & & 513 & 550 & 96,79 & 5,3 & \\
13 & 6 & 310 & 350 & 59,62 & 5,2 & 0,48 \\
& Total & 6299 & 6600 & & & \\
\hline
\end{tabular}

Resultado de los tratamientos con hexano

Tabla 13. Resultado de las extracciones y la grasa residual

\begin{tabular}{cc}
\hline $\begin{array}{c}\text { Número } \\
\text { Extracción }\end{array}$ & $\begin{array}{c}\% \text { grasa } \\
\text { residual }\end{array}$ \\
\hline 0 & 11,21 \\
1 & 5,23 \\
2 & 2,35 \\
3 & 1,85 \\
4 & 0,9 \\
6 & 0,81 \\
7 & 0,48 \\
\hline
\end{tabular}

ISSN:2617-9156 
Figura 4. Variación del \% de grasa residual con respecto al número de extracciones

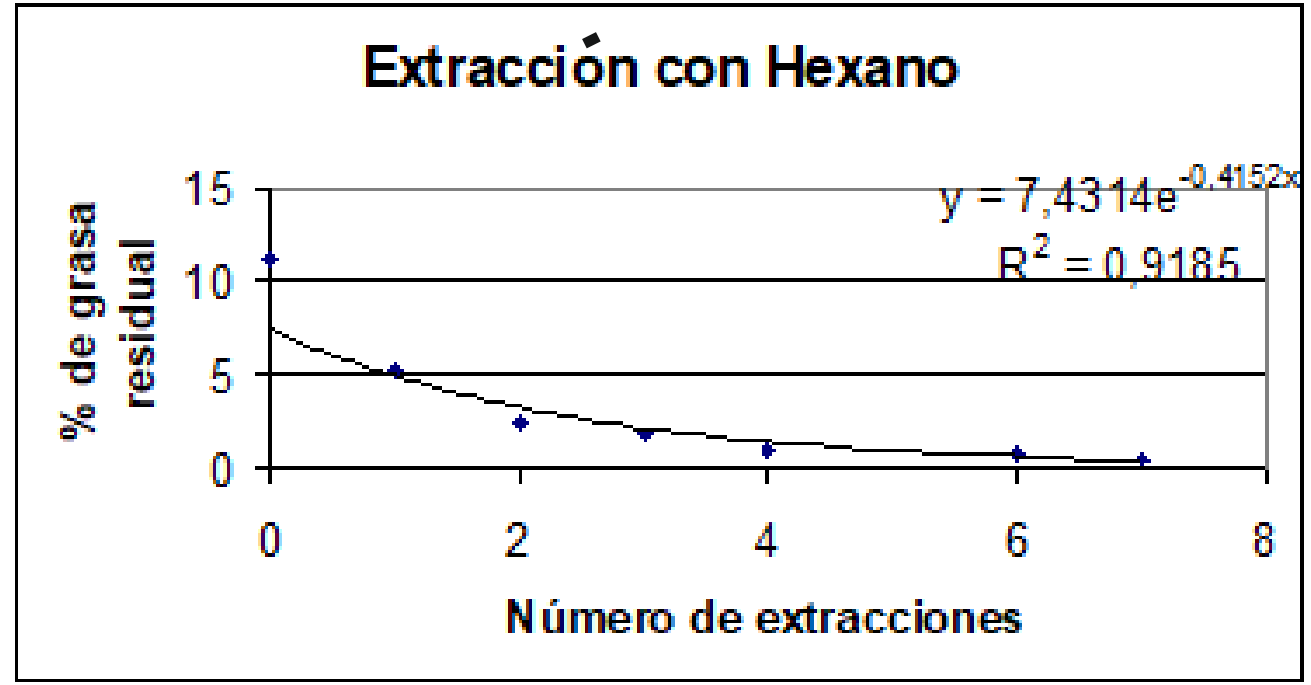

Balance de materiales realizado con hexano como solvente

Balance de materiales con una extracción

Tabla 14. Balance de materiales con una extracción

\begin{tabular}{|c|c|c|c|c|c|c|}
\hline Muestra & $\begin{array}{c}\mathrm{N}^{\mathrm{o}} \\
\text { Extracciones }\end{array}$ & $\begin{array}{c}\text { Peso } \\
\text { Filete }(\mathrm{kg})\end{array}$ & $\begin{array}{c}\text { Hexano } \\
\text { volumen }\end{array}$ & $\begin{array}{l}\text { Peso } \\
\text { final }\end{array}$ & Rendimiento & $\begin{array}{l}\text { \%grasa } \\
\text { residual }\end{array}$ \\
\hline 2 & & 455 & 500 & 89,22 & 5,1 & \\
\hline 3 & 1 & 380 & 400 & 69,09 & 5,5 & 5,23 \\
\hline & Total & 835 & 900 & 158,31 & $\begin{array}{c}\% \text { grasa inicial } \\
\text { \%grasa }\end{array}$ & 11,21 \\
\hline
\end{tabular}

Tabla 15. Balance de materiales con dos extracciones

\begin{tabular}{|c|c|c|c|c|c|c|}
\hline Muestra & $\begin{array}{c}\mathrm{N}^{\mathrm{o}} \\
\text { Extracciones }\end{array}$ & $\begin{array}{c}\text { Peso } \\
\text { Filete }(\mathrm{g})\end{array}$ & $\begin{array}{c}\text { Hexano } \\
\text { volumen }\end{array}$ & $\begin{array}{l}\text { Peso } \\
\text { final }\end{array}$ & Rendimiento & \%grasa \\
\hline 4 & & 810 & 800 & 150,00 & 5,4 & \\
\hline 5 & 2 & 550 & 500 & 103,77 & 5,3 & 2,35 \\
\hline & Total & 1360 & 1300 & 253,77 & $\begin{array}{c}\% \text { grasa inicial } \\
\text { \%grasa } \\
\text { eliminada }\end{array}$ & $\begin{array}{r}11,21 \\
79,04\end{array}$ \\
\hline
\end{tabular}

Tabla 16. Balance de materiales con tres extracciones

\begin{tabular}{|c|c|c|c|c|c|c|}
\hline Muestra & $\begin{array}{c}\mathrm{N}^{\mathrm{o}} \\
\text { extracciones }\end{array}$ & $\begin{array}{c}\text { Peso } \\
\text { Filete }(\mathrm{g})\end{array}$ & $\begin{array}{l}\text { Hexano } \\
\text { volumen }\end{array}$ & $\begin{array}{l}\text { Peso } \\
\text { final }\end{array}$ & Rendimiento & $\%$ grasa \\
\hline 6 & & 650 & 700 & 120,37 & 5,4 & \\
\hline \multirow[t]{3}{*}{7} & 3 & 520 & 500 & 94,55 & 5,5 & 1,85 \\
\hline & Total & 1170 & 1200 & 214,92 & $\begin{array}{c}\% \text { grasa inicial } \\
\text { \% grasa }\end{array}$ & 11,21 \\
\hline & & & & & eliminada & 83,50 \\
\hline
\end{tabular}


Balance de materiales con cuatro extracciones

Tabla 17. Balance de materiales con cuatro extracciones

\begin{tabular}{|c|c|c|c|c|c|c|}
\hline Muestra & $\begin{array}{c}\mathrm{N}^{\mathrm{o}} \\
\text { extracciones }\end{array}$ & $\begin{array}{c}\text { Peso } \\
\text { Filete }(\mathrm{g})\end{array}$ & $\begin{array}{c}\text { Hexano } \\
\text { volumen }\end{array}$ & $\begin{array}{l}\text { Peso } \\
\text { final }\end{array}$ & Rendimiento & $\%$ grasa \\
\hline 8 & & 450 & 500 & 81,82 & 5,5 & \\
\hline \multirow[t]{4}{*}{9} & 4 & 460 & 500 & 82,14 & 5,6 & 0,9 \\
\hline & Total & 910 & 1000 & 163,96 & & \\
\hline & & & & & $\begin{array}{c}\% \text { grasa inicial } \\
\% \text { grasa }\end{array}$ & 11,21 \\
\hline & & & & & eliminada & 91,97 \\
\hline
\end{tabular}

Balance de materiales con cinco extracciones

Tabla 18. Balance de materiales con cinco extracciones

\begin{tabular}{ccccccc}
\hline Muestra & $\begin{array}{c}\mathrm{N}^{\text {o }} \\
\text { extracciones }\end{array}$ & $\begin{array}{c}\text { Peso } \\
\text { Filete }(\mathrm{g})\end{array}$ & $\begin{array}{c}\text { Hexano } \\
\text { volumen }\end{array}$ & $\begin{array}{c}\text { Peso } \\
\text { final }\end{array}$ & Rendimiento & \%grasa \\
\hline 10 & & 278 & 300 & 47,93 & 5,8 & \\
11 & 5 & 923 & 1000 & 161,93 & 5,7 & 0,81 \\
& Total & 1201 & 1300 & 209,86 & $\begin{array}{c}\text { \% grasa inicial } \\
\text { \%grasa } \\
\text { elliminada }\end{array}$ & $\begin{array}{c}11,21 \\
\end{array}$ \\
& & & & & & \\
\hline
\end{tabular}

Balance de materiales con seis

Tabla 19. Balance de materiales con seis extracciones

\begin{tabular}{|c|c|c|c|c|c|c|}
\hline Muestra & $\begin{array}{c}\mathrm{N}^{\mathrm{o}} \\
\text { extracciones }\end{array}$ & $\begin{array}{c}\text { Peso } \\
\text { Filete }(\mathrm{g})\end{array}$ & $\begin{array}{c}\text { Hexano } \\
\text { volumen }\end{array}$ & $\begin{array}{l}\text { Peso } \\
\text { final }\end{array}$ & Rendimiento & \%grasa \\
\hline 12 & & 513 & 550 & 96,79 & 5,3 & \\
\hline \multirow[t]{4}{*}{13} & 6 & 310 & 350 & 59,62 & 5,2 & 0,48 \\
\hline & Total & 823 & 900 & 156,41 & & \\
\hline & & & & & $\begin{array}{c}\% \text { grasa inicial } \\
\text { \%grasa }\end{array}$ & 11,21 \\
\hline & & & & & eliminada & 95,72 \\
\hline
\end{tabular}

Composición química del concentrado proteico elaborado con filetes de jurel, y con seis extracciones con hexano.

Tabla 20. Composición proximal del Concentrado Proteico de jurel (filetes)

\begin{tabular}{llllll}
\hline Descripción & $\begin{array}{c}\text { Muestra } 1 \\
\%\end{array}$ & $\begin{array}{c}\text { Muestra } \\
\%\end{array}$ & $\begin{array}{c}\text { Muestra } \\
\%\end{array}$ & $\begin{array}{c}\text { Muestra } \\
\%\end{array}$ & $\begin{array}{c}\text { Muestra 5 } \\
\%\end{array}$ \\
\hline Humedad & 5,32 & 5,50 & 5,12 & 5,05 & 5,09 \\
Proteínas (N & 89,25 & 88,31 & 89,64 & 89,91 & 89,01 \\
x 6,25) & & & & & \\
Grasa & 0.91 & 0,88 & 0.91 & 0,98 & 0.97 \\
Cenizas & 2.75 & 2.45 & 2.56 & 2,78 & 2,64 \\
\hline
\end{tabular}




\section{DISCUSIÓN}

El proceso de obtención de concentrado proteico de pescado empleando solventes, utilizado en el presente estudio, permite obtener productos con bajo contenido graso, siendo lo particular del caso, que no se requiere de adición de calor para tal fin.

Se comprueba el efecto deshidratante del Etanol, al precipitar las partículas proteicas, durante su mezcla, produciéndose el fenómeno conocido desolvatación, lo cual es demostrado, por la perdida de peso de la masa molida al mezclarse con el Etanol y este reduce su grado alcohólico de $96^{\circ}$ GL ha un promedio de $70{ }^{\circ} \mathrm{GL}$, por incremento de agua. http://www.euita.upv.es/varios/ biologia/tecnicas_de_histologia_vegetal/ Documentos/Deshidratacion.htm

La masa precipitada de partículas proteicas al ser deshidratada por medios químicos, permite una mejor extracción de las grasas cuando se emplea el solvente hexano. Ya que el agua contenida en la materia interfiere en este proceso. La extracción de la grasa como puede apreciarse en las figuras respectivas sigue un curso exponencial.

De acuerdo a los principios dados por FAO, las proteínas obtenidas por este método califica como del tipo $\mathrm{B}$, al contener un contenido de grasa mayor al $0,75 \%$ y m e n o r a 1 3,00\%.https://es.scribd.com/doc/575419 04/ Aislados-y-Concentrados-Proteicosde-Pescado

\section{CONCLUSIONES}

Los rendimientos con respecto a la materia prima tienen los siguientes resultados: Para el filetes de jurel 5,4 kg de materia prima/ kg de concentrado.

La composición química proximal del Concentrado proteico de filetes de jurel fue el siguiente: humedad 5,21\%, proteínas $89,22 \%$, grasa $0.95 \%$, Cenizas $2.70 \%$.

Con los resultados obtenidos (Balance de Materiales y La Tecnología experimental) en la presente experiencia, se tiene la secuencia de operaciones unitarias que se emplean para obtener el producto, de forma tal que se tiene la base fundamental para la el diseño de una planta piloto.

\section{REFERENCIAS BIBLIOGRÁFICAS}

AOAC. (1984). Asociation of Oficial Analytical Chemist, fourteenth edition. Edited by Sidney Williams.

Guillen, R. (1980). Operaciones básicas de Obtención del Concentrado y su Aplicación en Galletas. Tesis para Optar al Título de Ingeniero Pesquero. Lima: Universidad Nacional Federico Villarreal.

Nishio, V. (1999) La Anchoveta. En http://www.rcp.net.pe/rcp/listas/w wws/oannes/oannes1.htm. Leído el 23/09/02.

Segura, L. (1994). Elaboración de pan fortificado con pulpa de merluza lavada. Tesis para optar al Título 
de Ingeniero Alimentario. Lima:

Universidad Nacional Federico

Villarreal. http://www.euita.

upv.es/varios/biologia/tecnicas_d

e_histologia_vegetal/Documento

$\mathrm{s} / \mathrm{Des}$ id rat a c i o n . h t m )

https://es.scribd.com/doc/575419

04/Aislados-y-Concentrados-

Proteicos-de-Pescado

CORRESPONDENCIA:

Blgo. José Candela Díaz

jose.candela@ulcb.edu.pe 